\title{
Socio-economic and Ecological Transition in Community Supported Agriculture: from the "transitional" to the "ideal" CSA
}

Authors: Roxana Bobulescu, Nhu Tuyên Lê, Claudio Vitari, Erin Whittingham

\begin{abstract}
This paper focuses on the transitional features of community supported agriculture (CSA). Its key contribution is to show the transformational potential of CSA for agricultural system change. The starting point of this research is the "ideal" CSA model. Instead of a monolithic CSA model, in practice we find a patchwork of experiences that we group together under the "transitional" CSA name. We develop a framework that highlights the "transitional" CSA model and compares it with both the conventional and the "ideal" CSA. The coevolutionary approach helps us to understand how CSAs adapt to their context. We use many narratives from the broad literature on CSAs.
\end{abstract}

Keywords : Community Supported Agriculture, "ideal" CSA, "transitional" CSA 


\section{Introduction}

A socio-ecological transition that implies a re-orientation of the economy and living styles toward a sustainable future society. Haberl et al. (2011) identified fundamentally different 'socio-metabolic' regimes like agrarian and industrial societies. So, if our times correspond to the transition from industrial society to a future sustainable society, then what can we infer about agriculture? As it appears obvious that our institutions have changed so drastically that we cannot go back to an agrarian, pre-industrial society, what will be the future agricultural regime? This question cannot be fully answered. But what we can do is identify transitional factors in the current state of agricultural institutions. The new agricultural regime can be called by a negation - "non-conventional" or by an affirmation - "agro-ecological". This non-conventional agricultural model is also called the "greening of the 'green revolution" (Polimeni et al., 2015). It is based on community building, on non-market activities such as risk sharing and benevolent work. This alternative model has gained momentum in many countries. Among the many resistance "grassroots initiatives", Community Supported Agriculture (CSA) organizations have been studied for almost four decades now. The growing number of CSAs triggered important literature. 
The CSA concept was born in the 1980s in the United States and has been expanded throughout the world. CSA is a "concept describing a communitybased organization of producers and consumers. The consumers agree to provide direct support to the local growers who will produce their food. The growers agree to do their best to provide a sufficient quantity and quality of food to meet the needs and expectations of the consumers." (Lamb, 1994: 39). The concept translates into multiple forms: consumer-directed, farmerdirected, farmer-coordinated, and farmer consumer cooperatives (Polimeni et al., 2015). Some authors insist upon the similarity of CSAs all over the world (Henderson and Van En, 2007; Gregson and Gregson, 2004), while others stress the diversity of CSAs (Goland, 2002). Recently, a paper presented the "ideal" CSA model through a case study in Belgium (Bloemmen et al., 2015). 
Even if the concept was born in the US, the North American CSA model has Japanese and European roots. At the origin of CSA, we find the cooperative movement. The Teikei system in Japan (1965) was a producer-consumer copartnership developed by a small group of Japanese women concerned with food safety, pesticides, processed and imported food, and the decrease of the small-scale farming population in Japan. They created an alternative to the market by developing a mutually supportive cooperation between consumer and producers. In Europe, the development of biodynamic farming was initiated by Rudolf Steiner (1861-1925). The biodynamic farm Buschbergerhof implemented Steiner's ideas in 1955. European associative economic relations started in the 1970s in Switzerland and Germany. Jan Vander Tuin traveled to study them and inspired by their practices, he founded the CSA farm Topinambour in Zurich in 1984. The producerconsumer food alliance was created in Geneva, and the CSA model developed, as more consumers became "shareholders".

Jan Vander Tuin introduces the idea to Robyn Van En at Indian Line Farm in South Egremont, Massachusetts, US and Susan Witt, director of the E. F. Schumacher Society in 1984. Two years later, the Temple-Wilton Community Farm and Indian Line Farm implemented the CSA idea as a way to integrate Schumacher's and Steiner's ideas. The CSA model spread from the east to west coast and grew internationally: Canada, Australia, New Zealand, Brazil, Argentina, Mali, and Togo. 
The present paper adopts the coevolutionary vision of ecological economics presented by Kallis and Norgaard (2010). Understanding change and transition means dealing with complexity in a non-determinist manner. Agro-environmental models coevolve through mutual interaction between social, economic and biophysical systems (Moreno-Penaranda, Kallis, 2010). We cannot have a monolithic CSA model, but a patchwork of CSAs conditioned by different cultural frameworks. For example, the US model of CSA appears more market-oriented than the European or Asian CSAs. The idea of CSA travels abroad and adapts to different social, economic, cultural, and environmental contexts, by transforming them in exchange. Coevolution looks at the conditions of change itself and sees the interactional, causal forces at work (see Kallis, Norgaard, 2010).

The agro-ecological transition is a dynamic process which introduces new mentalities, new behaviors, new actions. In the present paper, we aim to demonstrate that CSAs are catalysts of transition. In section 2 we present our comparative and coevolutionary approach to CSA. We introduce two CSA categories: the "ideal" and the "transitional". In section 3 we present the "ideal-type" of CSA. The patchwork of CSAs (called "transitional" CSA) is described in section 4 , in which we investigate the economic, social and natural behaviors in "transitional" CSAs. Section 5 develops the sustainability aspects common to both CSA categories. We conclude in section 6. 


\section{From the "transitional" to the "ideal" CSA}

In this article we adopt a coevolutionary approach of CSAs for a comparative analysis between existing practices. There are plenty of experiences and they are all strongly dependent on their context in social, cultural, and economic terms. "Coevolution provides a vocabulary that fuses ecological, economic and social processes and maintains openness to surprise in the face of the structural forces" (Moreno-Penaranda, Kallis, 2010: 778) The evolution of the CSA model shows a "patchwork of quilts" - a variety of practices in Norgaard's terms. Besides that, the practices change over time.

Bloemmen et al. (2015) investigated a Belgian self-harvest CSA, producing organic vegetables in a peri-urban area. The members of the CSA (farmer and the community of consumers) "co-produce through self-harvesting and they share risk (bad weather or other problems affecting production) in a trustful, cooperative and participative manner" (Bloemmen et al. 2015: 114). Their behavior departs from the mainstream neoclassical homo economicus and can be summed up by the holistic microeconomic agent's profile:

Table 1 The holistic microeconomic agent (Source: Bloemmen et al. 2015: 113) (see Appendix) 
These are the characteristic behaviors of an "ideal" CSA. The study adopts a holistic perspective of producers and consumers, based upon values like trust, cooperation and ecological responsibility as a result of collective initiatives of people sharing the same thoughts, values and motivation through their proposals of new ways of consuming, satisfying their needs and desires, organizing and transforming the social and collective life and the societies at large. The concept of "community" stands as a founding principle of developing sustainable post-growth economies.

Some of the CSAs share "ideal" features with the Belgian case, whilst others depart from the "ideal" case. Hence, we grouped all these different CSAs in a coevolutionary or "transitional" category (see Table 2).

\section{Table 2 Conventional, "Transitional" and "Ideal" CSAs (see Appendix)}

This multi-criterion, transitional model is a very large collection of cases. It has a foot in the conventional and the other in the unconventional model. The "transitional" CSA is very close to the "ideal" CSA in terms of sustainability and concern for healthy food (natural behavior). The economic and social behavior of members tend to differentiate the "transitional" from the "ideal" case the most. In both models we adopt a holistic view of the producer and the consumer. 
The boundaries between the conventional and the emerging new agricultural system are blurred. Global and local forces play concomitantly, and organic food production neighbors conventional farms. In the recent degrowth literature, two papers attempt to analyze the institutional dynamics of the emergence of alternatives or "concrete utopias" (Buch-Hansen, 2014, Joutsenvirta, 2016). Countless studies demonstrated that major institutional changes are no clear cut with the past (Buch-Hansen, 2014). Changes are path dependent, because existing institutions have self-reinforcing forces preventing brutal, radical reversals, and the power of marginalized actors over dominant structures is in some cases over-emphasized (Joutsenvirta, 2016). Coevolution shows how change is partly conditioned, though not determined, by a biophysical environment (Moreno-Penaranda and Kallis, 2010: 778).

In the following sections we present a comparative analysis between the "ideal" and the "transitional" CSAs.

\section{The "ideal" CSA}

\subsection{The Belgian self-harvest CSA}


Bloemmen et al. (2015) presented a Belgian self-harvest organic and periurban CSA that can be considered as an "ideal" CSA as it has an outspoken form of risk-sharing. In this particular case, one producer (the farmer) sells the products of the farm to a community of consumers. The total amount of vegetables that can be produced yearly is estimated at the beginning of the growing season. It is then divided in a number of "shares of harvest" to be sold to the community of consumers, who do themselves the harvesting on the farm. They pick only their share as the farm is always accessible. They trust the farmer, who trusts them too.

The price of the share covers the real production cost; thus, the consumers carry the production risks like bad weather conditions or bad health of the farmer. The main goal of the producer is not to make profits, but to balance total costs and total revenues. His/her remuneration is negotiated with the community of consumers at the beginning of the growing season. So, the consumers benefit from the best price of high quality food that is produced in a sustainable way. They also enjoy many social events on the farm and they have a very convivial way to spend their leisure time. As a result, "the farm acts as a catalyst for community building and knowledge transfer" (Bloemmen et al., 2015: 112). 
The number of consumers is stable over time, there is no pressure to maximize production because of the awareness of physical limits like the workforce of the farmer, the available spare-time of self-harvest consumers and the carrying capacity and fertility of soil. The producer searches to optimize the available resources such as water and sun. This CSA avoids over-exploitation of resources. Once optimal production is obtained there are no investments in new land or waged workforce. If there is a new demand, other entrepreneurs are encouraged to establish their own CSA if new land becomes available in the area.

The Belgian self-harvest CSA is also an agro-ecological farm. Some of the most relevant practices are: (1) the abolition of pesticides, herbicides, fungicides and fertilizers; (2) the plantation of trees and hedges around the farmland to increase biodiversity; (3) no-till and mulching for soil regeneration; and (4) crop rotation. Only local and seasonal vegetables are produced in respect of natural rhythms and metabolisms.

\subsection{Similar experiences of "ideal" CSA: an overview}

"Ideal" CSA production 
It has been widely acknowledged by researchers that for some members saving money is not the motivator for participation (Cone and Kakaliouras, 1995; Delind and Ferguson, 1999; Durrenberger, 2002; Landis et al., 2010) nor is making money the driving force for farmers (Galt, 2013; Jarosz, 2011). This is quite a large departure from traditional businesses that tend to seek profit maximization as a goal.

Competition is not a common concern among farmers of CSA either. A university-based CSA in Montana, US recommends other CSAs to members when they do not have any availability (Wharton and Harmon, 2009). The farmer of Walnut Acres Subscription Produce in Iowa, US reports she does not feel in competition with other CSAs and sends potential members to other CSAs when their goals do not align (Janssen, 2010). This lack of a concern of competition among CSA farmers does not align with how share prices are set. 
Brown and Miller (2008) acknowledge that many CSA organizers determine the share price based on a perception of how much members are willing to pay. A core group at a CSA in New York, US set the share price relative to grocery store prices in fear of member's comparing the two (Wodraska, 2008). This leads one to think that some CSAs are concerned of losing members to other lower priced CSAs. Nevertheless, other CSAs set the share price based-off production costs. At Temple-Wilton Community Farm, one of the first CSAs in the US, the share price was set by first assessing how much capital was needed and then each member declaring how much they were able to contribute until the budget was met (Wodraska, 2008). This first step of ensuring costs are covered demonstrates an honest commitment to financially support the farmer. The second step of allowing members to decide what they can contribute shows a strong community that has created its own way to deal with income disparities while giving everyone equal access to participate.

One farm in New York, US, that has the objective of providing shares to lowincome households, implemented techniques, e.g. a compost heated greenhouse, collecting fertilizer from another farm for free, as a means to keep costs low as well as practice sustainable methods (Forbes and Harmon, 2007). 
As members give money in advance of receiving the produce it shares the risk of farming among all participants. This denotes a large departure from traditional economics as it means the participants financially share the production costs regardless of output. A member at a CSA in Minnesota, US understands risk sharing to mean something personal as well: "I am willing to take a stand by putting my money out there at the beginning of the season to say, "I'm with you, farmer." And whatever weather gives us, whatever crops look like this year, I'm with you" (Cone and Kakaliouras, 1995: 31). Members have also shared the financial risks of farming by taking measures to look after the farmer. At a highly successful CSA in Massachusetts, US the members promoted the idea of giving the farmer social benefits such as medical insurance and a retirement plan (Roth and Keen, 1999).

The last emerging characteristic with economic implications is decommodification through the practice of de-standardization. Destandardization is evident in the example of a farmer of one of the largest CSAs in Iowa, US who purposely bundles different sizes and shapes of a fruit or vegetable together to show the realities of farming (Janssen, 2010). This action is a form of education that challenges the consumer to rethink what is normal and works towards desensitizing them from imperfections. 
Trust also exists between farmers. Cases studies of CSAs have reported farmers exchanging or buying produce with other farmers without written contracts (Janssen, 2010; Nost, 2014). These examples show trust existing between many different actors in CSA, ie. farmer and member, farmer and farmer, and farm and greater community. Despite this diversity, characteristics like trust and personal relationships within the field show a departure from typical consumer - producer relationships.

"Ideal" CSA consumption: the community

An expected characteristic of an "ideal" CSA is strong community engagement and building (Pole and Gray, 2013; Feagan and Henderson, 2009). 
In the case presented by Sumner et al. (2010) of Fourfold CSA in Ontario, Canada community building is a priority. The authors found events and activities to be a necessity as they built culture, which led to member engagement and retention, and ultimately the ability of the CSA to remain in operation (Sumner et al., 2010). Another study that looked into member's motivation and participation and the role of women found participation to "[correlate] with a broader understanding of the implications of CSA and with a greater commitment to its ideals" (Cone and Myhre, 2000: 13). Hence, CSAs should encourage community building and target their members in assuring that they really share the farmer's mission. In the example of a CSA in Illinois, US in the early 2000s, members left one CSA for another specifically for its social activities and sense of community that was fostered by the farmer (Mcllvaine-Newsad et al., 2004). Galt (2013) finds similar sentiments from many farmers in his study of 54 CSAs in California, US. One in particular expresses "the point of what we are trying to do is much bigger than grow food and make money - I mean that's not even the point. It's to live sustainably and create communities that are growing their own food" (26-27). The CSA of Ann Arbor in Michigan, US in the late 1980s prioritized community building by reducing membership numbers, and consequently revenue, by nearly half to maintain a sense of community (Donahue, 1994). This shows the importance of nonmonetary benefits over profit maximization. 
The social interactions occurring within CSA show signs of trust, and it extends much further than the obvious form of members paying upfront and trusting the farmer to do his/her best in producing with that money. For example, how shares are bundled shows the relevance of trust when deciding how the act will be done. A CSA in Kentucky, US originally ]allowed members to take the quantities and bundle their own shares (Nost, 2014). However, due to the pick-up location moving off-site and previous problems of some members taking more than indicated the farmer switched to pre-packaging the shares (Nost, 2014). Alternatively, at a CSA in an intentional community in Ireland, the members take as much and as frequently as they want with the idea that they only take what they need (Moore et al., 2014). Trust is also present within this CSA's relationship with the greater alternative food movement. Due to a less-thanexpected amount of produce the CSA borrowed produce from a biodynamic farm with promises that it would return it in the future (Moore et al., 2014).

\section{The "transitional" CSA}

\subsection{The producer}


Not all farmers are quite as comfortable with the element of risk sharing. As one farmer puts it, "you get paid up front but that also means that you have commitment up front to provide a basket full of fresh, delicious produce. We have a capitalistic model here and if your subscriber doesn't like it, you are going to lose them. There is a pressure to produce week after week after week." (Galt, 2013: 24-25). This farmer recognizes the difficult position of operating an alternative initiative within the conventional system. The farmer also highlights the pressures of what is supposed to be a benefit of the alternative system. To address the unreliability of farming some farmers supplement their boxes from other farmers to offset small baskets instead of sharing the risks (Galt, 2013; Moore et al., 2014; Nost, 2014). Galt (2013) found that $13 \%$ of farmers in his study of 54 CSAs in California, US do it all the time while $44 \%$ do it sometimes.

The difference between operating costs and revenue has economic implications for the farmer. It was discovered in the 2001 US national survey of CSAs that the majority of farmers believed their CSA helped in their ability to meet the operating costs of their farms as a whole (Lass et al., 2003). Nevertheless, the majority of farmers were unsatisfied with their financial compensation and security, eg. retirement and health insurance, from the farm as whole, and just over half of the farmers believed their CSA operation improved their compensation (Lass et al., 2003). 
This illustrates that Steiner's principle of risk sharing is not always practiced as the farmers assume the risk financially and personally. What these examples illustrate though is that it is the farmer who bears the pressures of risk sharing and at times it is the inability of the farmer to share the risk.

Regardless of the challenges inherent in risk sharing the economic model that it supports is what entices many new farmers. After being unable to receive funds to start an organic farm a farmer near Inverness, Scotland, opted to start a CSA because of the upfront financial support (Cox et al., 2008). He emphasizes to the members (consumers) that they are buying a portion of the yield and not guaranteed baskets of produce. The farmer has found that some members do not fully understand what it means to share the risks. Likewise, a study gauging non-members appetite for CSA in Australia found that some respondents were apprehensive about the idea of not receiving what they paid as result of unexpected circumstances (Lea et al., 2006). 
There do seem to be regional and cultural implications for the concept of risk sharing within CSA. The organizers at Little Donkey Farm in Beijing, China have not been able to implement the idea of paying for a part of the harvest but instead have had to guarantee a minimum that will be received due to mistrust between producers and consumers in the capital city (Shi et al., 2011). However, in Croatia risk sharing is a big incentive for farmers to adopt a CSA model as it addresses their issue of finding a market for their produce (Sarjanović, 2014). 
The non-market approach of "ideal" CSAs introduces the decommodification and de-standardization of the agricultural produce, but destandardization is not accepted by all members, neither. In a study of member's experiences and eating habits pre- and post-season at a CSA in Ohio, US members stated they understood that the produce might look different and may not be as clean as produce from the grocery store, while some members still hoped it would be clean (Goland, 2002). Nevertheless, in the post-season survey many members expressed dissatisfaction as they felt they "received inferior produce, while the better (bigger, cleaner) vegetables were" sold at the farmer's roadside stand (Goland, 2002: 19). This shows a divergence in the goal of de-commodification by some farmers and members. While Goland's (2002) study shows some members do not expect the produce to be the same, it is possible, once they experience the imperfections, they are still sensitive to them. It would seem that decommodification in this case will not be realized until the member accepts the de-standardization. It would appear that some farmers are working towards de-commodification while others still adhere to conventional standards, and that the member has not fully accepted what agriculture really looks like.

\subsection{The Consumer}

Community building 
Nonetheless, doubts exist about the universality of the community potential. As one member in a study of a CSA in Ontario, Canada, expressed, "I've been a couple of times to the all-day music events and it's OK, but it's not my thing. .... For me, that's not what I'm looking for. .... it's much more about supporting [the founders] personally and supporting organic agriculture" (Sumner et al., 2010: 6). Brehm and Eisenhauer (2008) and Cappellano (2011) found in their study of two CSAs in eastern US that quality and safe food were the most important motivators for participating, while community building was ranked much lower. Consistently throughout CSA research similar stories have been told of member's main motivations for participating being safe food (Cone and Kakaliouras, 1995; DeLind 1999; Hinrichs and Kremer 2002; Kolodinsky and Pelch, 1997; Pole and Gray, 2013; Sarjanović, 2014).

Voluntary work and participation 
The property of voluntary work and participation has received criticism from CSA organizers and researchers alike. Voluntary work was present in one of the original CSAs, Temple Wilton Community Farm, as there was no distinction between roles. All members were called farmers and all were expected and had agreed to work on the farm (Wodraska, 2008). Member involvement has taken on new forms since. Some CSAs have implemented mandatory work requirements to spread the effort required of farm work while indirectly trying to foster community building (DeLind, 1999; Wodraska, 2008). Another study of labor within CSA found members would rather pay the full share price instead of working on the farm (Janssen, 2010). This perception is confirmed by a member at a CSA in Michigan, US where work requirements were implemented to spur interaction between participants. The member felt her money could make-up for her inability to complete the work requirement (DeLind, 1999). The idea to build community in this way can be undermined by the CSA organizers themselves. Roxbury Farms in New York, US, one of the largest CSAs in the country in 2006, offered the option for members to opt-out of their work requirements by paying extra (Polimeni et al., 2006). A CSA founded in 1994 in Scotland also allowed members to pay more to forgo their work shifts (Cox et al., 2008). Other studies have shown member dissatisfaction with volunteering (Durrenberger, 2002; Farnsworth et al., 1996), and this demonstrates that some members are willing to give financially but not necessarily their time. 
Nevertheless, voluntary work and participation is present within CSA. Members volunteer their time by helping with administrative tasks, e.g. accounting, legal advice, recruitment, advertising, organizing distribution sites, and physical labor. Members report satisfaction and enjoyment from working on the farm (Chen, 2013; Zepeda et al., 2014). One study of working share members at Little Donkey Farm in Beijing, China found members reporting "being happy, feeling free, life enrichment, stress relief, and sense of accomplishment" as a result of working on the farm (Chen, 2013: 40). The members also reported that their participation in growing their food led to new social connections, enhancing existing relationships with friends and family, and educational opportunities for themselves and their children (Chen, 2013). These benefits show the importance and relevance of this characteristic.

Voluntary work and participation also benefit the CSA movement as a whole. Chesapeake CSA in Eastern US relied on volunteers to run the farm, all members to supply labor, and a core group to support the farmer (Lang, 2010). However, once the organizational structure changed due to an NGO assuming responsibility for the CSA its objectives drifted from community building goals to enhancing accessibility of quality food (Lang, 2010). As a result, member participation at events and within the organization declined, and member commitment to the CSA goals decreased (Lang, 2010). 
The CSA characteristics of voluntary work and participation also help in alleviating the accessibility and exclusivity issue within CSA. Future Farm CSA in New York, US whose objective is to provide shares for low-income individuals is able to offer a low share price because of the volunteer labor (Forbes and Harmon, 2007).

\section{Sustainability - a common feature}

Another main reason for the success of CSA is that it deals with many concerns about food security in developing countries, subsidized agriculture, peak oil, peak farmland, peak fertilizer (phosphates), energy intensity of industrialized processes, and agricultural bioterrorism threat. Polimeni et al. (2015) call for a "green revolution" in order to decouple agricultural production for food from the agricultural production of energy (biofuels). CSAs can contribute to this greening of the green revolution in agriculture. 
Ecological sustainable practices consistently seem to be a priority for participants (according to testimonies in Charles, 2011; Galt, 2013; Hall et al., 2013; Press and Arnould, 2011; Sarjanović, 2014; Schnell, 2013; FarrWharton et al., 2012). The concept of ecological sustainability stems from Steiner's idea of biodynamics, which has guided the emphasis on ecology within CSA and has grown to include organic and permaculture methods. Lang's (2005) survey of 204 members of five mid-Atlantic CSAs in 2000 showed that member satisfaction is positively correlated with nonconventional agricultural practices. Complementary, an online study of 565 CSAs in New York, US in 2010 found that the main motivation for joining a CSA was the local, fresh and organic products (Pole and Gray, 2013).

Goland (2002) shows the importance of environmental awareness in member retention. It shows that members join originally to access safe food, but through their participation their motivations expand and so do their concern for the environment. This further illustrates the importance of retention for the CSA movement in how it not only financially sustains it, but also strengthens member commitment to its ideals. Overall, if possible to combine the findings from Goland's (2002) and Cox et al.'s (2008) studies it would appear that ecological sustainability goals are important for members to have initially, but if not then they will develop with time if the member is engaged long enough. 
This focus on sustainability is also a priority for all the farmers in Cone and Myhre's (2000) study of eight CSAs in Minnesota, US from 1993 to 1998. The authors note that the farming practices "required careful observation, experimentation, flexibility, and a breadth of knowledge regarding diversity of soil, plants, insects, and animals as well as appropriate forms of mechanical and organic technology" (Cone and Myhre, 2000: 11). In these examples, environmental sustainability is the goal, and it is because of the farmers personal principles that they choose to operate this way. Effort, time, efficiency, are all sacrificed in order to mill the fields by hand or use natural compost over easily attained synthetic. In this way, CSA principles can contribute to the greening of the green revolution in agriculture.

The size of CSA farms may also be a contributing factor that allows farmers to be dedicated to sustainability as conventional farms are considerably larger than a CSA farm (Schnell, 2007). Being smaller may allow for more labor- and time- intensive practices that would be difficult for larger conventional farms.

The equipment used is also a contributing factor. Cooley and Lass (1998) give an example of one CSA farmer in Massachusetts, US in 1995 who did physical labor instead of mechanizing as a result of his principles. This shows the environment being a priority over efficiency. Alternatively, the farmer at Harvest Share CSA in Iowa, US, began using some tractor once physical labor limited production quantities, and was able to significantly increase production as a result (Janssen, 2010). 
Despite the priority given to practicing safe farming techniques farmers often intentionally avoid organic certification (Lang, 2010; Schnell, 2007; Shi et al., 2011; Moore et al., 2014). For example, Little Donkey in Beijing, China, and a CSA created in 2008 by an intentional community in Ireland both follow permaculture, organic, or biodynamic practices yet do not receive the organic certification (Shi et al., 2011; Moore et al., 2014). Such reasons as cost and time consuming are given by Lang (2010) as to why a CSA in Maryland, US avoided the certification process.

As food democracy (Hassanein, 2003) spreads as a result of many social movements, the newcomers' profiles differ from those of the 1970s original groups. CSAs may attract these new waves of interest because, as one farmer in Iowa, US believes, CSAs give farmers and members a place to demonstrate their beliefs (Wells et al., 1999). Therefore, the farmer sees the CSA as a gathering point for ecological concerns and interprets member's participation as resisting conventional agriculture. DeLind and Ferguson (1999) report many members participated as a way to oppose "a faceless, agri-food industry and a competitive, consumerist mentality" and "a largescale, centralized, corporately structured capitalism" (9).

This is confirmed by one member who participates in a CSA in North East England as its philosophy aligns with his. "(CSA) fitted tightly with my value system and belief in sustainability" (Charles, 2011: 367).

\section{Conclusion}


The CSA is a catalyst of the agroecological transition. This paper attempted to identify the transitional factors in various CSAs. Two types of CSA have been established: the "ideal" and the "transitional". The "ideal" type is a small scale, local, risk-sharing, non-market community-based CSA. The "transitional" type is a quasi-market, local, partially risk-sharing, with some community participation. The "transitional" type shares features with the conventional and the "ideal" type of agricultural models.

Our categorization was established based on the holistic microeconomic behavior as defined by Bloemmen et al. (2015): non-maximising, non profitseeking, small scale, quality versus quantity (economic behavior); sympathy, conviviality, cooperation, community participation (social behavior) and responsibility towards nature (natural behavior). 
We can sum up some of the main findings. Firstly, ecological sustainability is at the core of the CSA movement. It is the founding principle gathering the participants. Its expression is the organic farming inspired by Steiner's biodynamics and sustainability requirements in production, transport, and consumption. It produces healthy, high quality food in a sustainable way. Secondly, even in "transitional", CSAs, the economic model has to adapt to ecological concerns. It promotes local economies, very low or no competition, share price determination for supporting the farmer, some risksharing between members, and de-commodification and de-standardization of the production. Thirdly, the social model relies on trust, community building, and voluntary work. The participant objectives presented in this paper demonstrate a sense of ecological, economic, and social responsibility. All these combined represent a greater mission of "resistance to mainstream notions of growth and development" and thus an attempt to transform society (DeLind and Ferguson 1999: 9). CSAs adopt a holistic perspective of producers and consumers, based upon values like trust, cooperation and ecological responsibility as a result of collective initiatives of people sharing the same thoughts, values and motivation. This is done through their proposals of new ways of consuming, satisfying their needs and desires, organizing and transforming the social and collective life and the societies at large. Hence, the CSA practices have a transformational potential, while at the same time the pragmatism and diversity in CSA evolution reveal the transitional factors inherent to social change. 
There is a progressive social transformation going on. And as in any transformational institutions, members have a foot in the conventional model and the other in the CSA model.

CSAs share a sense of ecological, economic, and social responsibility. Nonetheless, their relative importance is a question of degree and these differences in degrees are maybe related to the diverse acknowledgment and adherence to Steiner's and Schumacher's principles or the emergence of other alternative emerging ethics.

Future research should focus on the root ethical principles of CSA to understand their influence on CSA practices. CSAs future and especially their transformational power will depend on the CSA commitment to the original values.

\section{References}

Bloemmen, M., Bobulescu, R., Le N.T., Vitari, C., 2015. Microeconomic degrowth: the case of community supported agriculture. Ecological Economics 112, 60-68.

Brehm, J.M., Eisenhauer, B.W., 2008. Motivations for participating in community-supported agriculture and their relationship with community attachment and social capital. Southern Rural Sociology 23, 94-115.

Brown, C., Miller, S., 2008. The impacts of local markets: a review of research on farmers markets and community supported agriculture (CSA). American Journal of Agricultural Economics 90, 1298-1302. 
Buch-Hansen, H., 2014. Capitalist diversity and de-growth trajectories to steady-state economies. Ecological Economics 106, 167-173.

Cappellano, K.L., 2011. Supporting Local Agriculture: Farmers Markets and Community-Supported Agriculture and Gardens. Nutrition Today 46, 203207.

Charles, L., 2011. Animating community supported agriculture in North East England: Striving for a "caring practice." Journal of Rural Studies 27, 362371.

Chen, W., 2013. Perceived value of a community supported agriculture (CSA) working share. The construct and its dimensions. Appetite 62, 37-49.

Cone, C. A., Kakaliouras, A., 1995. Community Supported Agriculture: Building Moral Community or an Alternative Consumer Choice. Culture \& Agriculture 15, 28-31.

Cooley, J.P., Lass, D.A., 1998. Consumer benefits from community supported agriculture membership. Review of Agricultural Economics 20, 227-237.

Cox, R., Holloway, L., Venn, L., Dowler, L., Hein, J.R., Kneafsey, M., Tuomainen, H., 2008. Common ground? Motivations for participation in a community-supported agriculture scheme. Local Environment 13(3), 203218.

DeLind, L.B., 1999. Close encounters with a CSA: The reflections of a bruised and somewhat wiser anthropologist. Agriculture and Human Values $16,3-9$. 
DeLind, L.B., Ferguson, A.E., 1999. Is this a women's movement? The relationship of gender to community-supported agriculture in Michigan. Human organization 58, 190-200.

Donahue, T.P., 1994. Community-supported agriculture: Opportunities for environmental education. The Journal of Environmental Education 25, 4-8.

Durrenberger, E.P., 2002. Community supported agriculture in Central Pennsylvania. Culture \& Agriculture 24, 42-51.

Farnsworth, R.L., Thompson, S.R., Drury, K.A., Warner, R.E., 1996. Community supported agriculture: filling a niche market. Journal of food distribution research $27,90-98$.

Farr-Wharton, G., Lyle, P., Choi, J.H.-J., Foth, M., 2012. Health matters for subscribers to community-supported agriculture. Food and Public Health 2, 184-192.

Feagan, R., Henderson, A., 2009. Devon Acres CSA: local struggles in a global food system 26, 203-217.

Forbes, C.B., Harmon, A.H., 2007. Buying into community supported agriculture: strategies for overcoming Income barriers. Journal of Hunger \& Environmental Nutrition 2, 65-79.

Galt, R.E., 2013. The Moral Economy Is a Double-edged Sword: Explaining Farmers' Earnings and Self-exploitation in Community-Supported Agriculture. Economic Geography 89, 341-365.

Goland, C., 2002. Community supported agriculture, food consumption patterns, and member commitment. Culture \& Agriculture 24(1), 14-25. 
Gregson, B., Gregson, B., 2004. Rebirth of the Small Family Farm: A Handbook for Starting a Successful Organic Farm Based on the Community Supported Agriculture Concept. Acres USA, Austin, Texas.

Haberl, H., Fischer-Kowalski, M., Krausmann, F., Martinez-Alier, J., Winiwarter, V., 2011. Sustainable Development 19, 1-14.

Hall, K., Meyers, C., Doerfert, D., Akers, C., Johnson, P., 2013. Recruiting and retaining shareholders for community supported agriculture in Texas. Journal of applied communication.

Hassanein, N., 2003. Practicing food democracy: a pragmatic politics of transformation. Journal of Rural Studies 19, 77-86.

Henderson, E., Van En, R., 2007. Sharing the Harvest: A Citizen's Guide to Community Supported Agriculture. Chelsea Green Publishing Company, White River Junction, Vermont.

Hinrichs, C., Kremer, K.S., 2002. Social Inclusion in a Midwest Local Food System Project. Journal of Poverty 6, 65-90.

Janssen, B., 2010. Local Food, Local Engagement: Community-Supported Agriculture in Eastern Iowa. Culture \& Agriculture 32, 4-16.

Jarosz, L., 2011. Nourishing women: toward a feminist political ecology of community supported agriculture in the United States. Gender, Place \& Culture 18, 307-326.

Joutsenvirta, M., 2016. A practice approach to the institutionalization of economic degrowth. Ecological Economics 128, 23-32. 
Kallis, G., Norgaard, R. B., 2010. Coevolutionary ecological economics. Ecological Economics 69, 690-699.

Kolodinsky, J.M., Pelch, L.L., 1997. Factors Influencing Consumer Satisfaction with a Community Supported Agriculture Farm (CSA). Journal of Consumer Satisfaction, Dissatisfaction and Complaining Behavior. 10, 131-138.

Lamb, G., 1994. Community Supported Agriculture. Threefold Review 11: 39-43.

Landis, B., Smith, T.E., Lairson, M., Mckay, K., Nelson, H., O’Briant, J., 2010. Community-supported agriculture in the Research Triangle Region of North Carolina: demographics and effects of membership on household food supply and diet. Journal of Hunger \& Environmental Nutrition 5, 70-84.

Lang, K.B., 2010. The Changing Face of Community-Supported Agriculture. Culture \& Agriculture 32, 17-26.

Lang, K.B., 2005. Expanding our understanding of community supported agriculture (CSA): An examination of member satisfaction. Journal of Sustainable Agriculture 26(2), 61-79.

Lass, D., A. Brevis, G.W. Stevenson,J. Hendrickson, Ruhf. K., 2003. Community Supported Agriculture Entering the 21st Century: Results from the 2001 National Survey. University of Massachusetts, Amherst, MA: Dept. of Resource Economics. 
Lea, E., Phillips, J., Ward, M., Worsley, A., 2006. Farmers' and Consumers' Beliefs About Community-Supported Agriculture in Australia: A Qualitative Study. Ecology of Food and Nutrition 45, 61-86.

Mcllvaine-Newsad, H., Merrett, C.D., McLaughlin, P., 2004. Direct from farm to table: Community supported agriculture in Western Illinois. Culture \& Agriculture 26, 149-163.

Moore, O., McCarthy, O., Byrne, N., Ward, M., 2014. Reflexive resilience and community supported agriculture: The case that emerged from a place. Moreno-Penaranda, R., Kallis, G., 2010. A coevolutionary understanding of agroenvironmental change: A case-study of a rural community in Brazil. Ecological Economics 69, 770-778

Nost, E., 2014. Scaling-up local foods: Commodity practice in community supported agriculture (CSA). Journal of Rural Studies 34, 152-160.

Pole, A., Gray, M., 2013. Farming alone? What's up with the " $\mathrm{C}$ " in community supported agriculture. Agriculture and Human Values 30, 85100.

Polimeni, J.M., Iorgulescu, R. I., Shirley, R. L., 2015. Travelling Back to Sustainable Agriculture in a Bioeconomic World. The Case of Roxbury Farm CSA. Nova Publishers, NY.

Polimeni, J.M., Polimeni, R.I., Shirey, R.L., Trees, C.L., Trees, W.S., 2006. The supply of community supported agriculture. Journal of Business \& Economics Research (JBER) 4. 
Press, M., Arnould, E.J., 2011. Legitimating community supported agriculture through American pastoralist ideology. Journal of Consumer Culture 11, 168-194.

Roth, C., Keen, E., 1999. Community-supported Agriculture: Organizing a Successful CSA.

Sarjanović, I., 2014. The role of community supported agriculture in the development of organic agriculture in Croatia. Geoadria 19, 1-25.

Schnell, S.M., 2013. Food miles, local eating, and community supported agriculture: putting local food in its place. Agriculture and Human Values $30,615-628$.

Schnell, S.M., 2007. Food with a farmer's face: Community-supported agriculture in the United States. Geographical Review 97, 550-564.

Shi, Y., Cheng, C., Lei, P., Wen, T., Merrifield, C., 2011. Safe food, green food, good food: Chinese Community Supported Agriculture and the rising middle class. International Journal of Agricultural Sustainability 9, 551-558. Sumner, J., Mair, H., Nelson, E., 2010. Putting the culture back into agriculture: civic engagement, community and the celebration of local food. International journal of agricultural sustainability 8, 54-61.

Wells, B., Gradwell, S., Yoder, R., 1999. Growing food, growing community: community supported agriculture in rural Iowa. Community development journal 34, 38-46. 
Wharton, C., Harmon, A., 2009. University engagement through local food enterprise: community-supported agriculture on campus. Journal of Hunger \& Environmental Nutrition 4, 112-128.

Wodraska, W., 2008. Three CSAs, three economies: Personal, practical comparison of three models of community supported agriculture. Biodynamics 264, 44.

Zepeda, L., Reznickova, A., Russell, W.S., Hettenbach, D., 2014. A Case Study of the Symbolic Value of Community Supported Agriculture Membership. Journal of Food Distribution

Research 45. 
Appendix (Tables, figures, images)

Table 1 The holistic microeconomic agent (Source: Bloemmen et al. 2015: 113)

\begin{tabular}{|l|l|}
\hline Economic behavior & $\begin{array}{l}\text { Non-maximising, non profit-seeking } \\
\text { (profit is a means to an end), } \\
\text { searching quality versus quantity, } \\
\text { small scale }\end{array}$ \\
\hline Social behaviour & $\begin{array}{l}\text { Sympathy, conviviality, } \\
\text { cooperation, community } \\
\text { participation }\end{array}$ \\
\hline Natural behaviour & Responsibility towards nature \\
\hline
\end{tabular}


Table 2 Conventional, "Transitional" and "Ideal" CSAs

\begin{tabular}{|c|c|c|c|}
\hline $\begin{array}{c}\text { Agricultural } \\
\text { models / Holistic } \\
\text { microeconomic } \\
\text { agent's behavior }\end{array}$ & Conventional & $\begin{array}{c}\text { "Transitional" } \\
\text { CSA }\end{array}$ & "Ideal" CSA \\
\hline
\end{tabular}




\begin{tabular}{|c|c|c|c|}
\hline Economic behavior & $\begin{array}{l}\text { Market-driven } \\
\text { Global } \\
\text { No-risk } \\
\text { sharing } \\
\text { Commodificati } \\
\text { on and } \\
\text { standardizatio } \\
\text { n }\end{array}$ & $\begin{array}{l}\text { Quasi-market } \\
\text { Local } \\
\text { Partial risk- } \\
\text { sharing }\end{array}$ & $\begin{array}{l}\text { Non-market } \\
\text { Local } \\
\text { Risk-sharing }\end{array}$ \\
\hline Social behavior & No community & $\begin{array}{c}\text { Some } \\
\text { community } \\
\text { participation }\end{array}$ & $\begin{array}{l}\text { Strong } \\
\text { community, } \\
\text { conviviality, } \\
\text { cooperation }\end{array}$ \\
\hline Natural behavior & Unsustainable & $\begin{array}{l}\text { Sustainable, } \\
\text { concern for food } \\
\text { safety and } \\
\text { security }\end{array}$ & $\begin{array}{l}\text { Biodynamic, } \\
\text { organic, } \\
\text { permaculture, } \\
\text { food democracy }\end{array}$ \\
\hline
\end{tabular}

